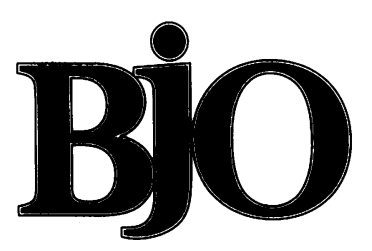

British Journal of Ophthalmology

\title{
Editorials
}

\section{What is the best primary surgical treatment for the infantile glaucomas?}

The infantile glaucomas are a rare group of disorders. It is estimated that a consultant ophthalmologist in the UK would expect to see one new case of primary congenital glaucoma approximately every 5 years. In certain parts of the world, consanguineous marriages are more common and this may result in a higher incidence of infantile glaucoma. $^{1}$ However, despite their rarity, this group of conditions accounts for a disproportionate percentage (up to $18 \%$ ) of children in blind schools around the world. ${ }^{2}$ Furthermore, it has been estimated that of approximately 300000 individuals affected by this group of conditions worldwide, two thirds are blind. ${ }^{3}$ Given that most of these patients have normal life expectancies, there are not many ophthalmic disorders in which successful treatment is more important in terms of the dramatic long term effects on the patients and their families.

In this issue of the journal (p 499) Fulcher and colleagues report a partial follow up study of patients treated with primary trabeculectomy for infantile glaucoma. They report very good long term results for primary trabeculectomy without antiscarring agents at one tertiary referral centre. Trabeculectomy has the advantage of being an operation that is commonly performed by most ophthalmologists. However, primary trabeculectomy is not entirely straightforward in childhood glaucoma. The eye is large and the limbal anatomy is often very distorted. Lack of familiarity with these unusual eyes can lead to complications such as iris and ciliary body incarceration and vitreous loss. ${ }^{4-6}$ In one series in which primary trabeculectomy was performed by general ophthalmologists only 10 out of 27 procedures were successful $(37 \%) .^{5}$ Ten of the failed procedures had a degree of iris/ciliary body incarceration in the sclerostomy. Elder found a success rate of approximately $55 \%$ at 5 years in Palestinian Arab children treated by trabeculectomy performed by general ophthalmologists. $^{6}$

The other problem with primary trabeculectomy is that the superior conjunctival area is used. Even 5 years after successful surgery, with a normal life expectancy, there is a high likelihood that a significant proportion of these patients will need further surgery within their lifetimes. Although the one failed eye with primary congenital glaucoma responded to a second trabeculectomy, there is no question that eyes that have had previous conjunctival surgery including failed trabeculectomy have a higher failure rate in the long term. ${ }^{78}$ Furthermore, none of the patients in this series presented before 3 months, had corneal diameters greater than $14 \mathrm{~mm}$, or were non-white and only one out of 20 eyes had an intraocular pressure greater than $28 \mathrm{~mm} \mathrm{Hg}$ (although the anaesthesia may have lowered the pressure). These factors are associated with a worse surgical prognosis.' It is interesting that the two eyes with primary congenital glaucoma in the earlier series by Burke and Bowell which failed trabeculectomy and required multiple procedures after initial trabeculectomy had corneal diameters of $14.5 \mathrm{~mm}^{10}$

The advent of antiscarring agents, particularly the antimetabolites, has revolutionised trabeculectomy in the refractory glaucomas. In view of their good results, the authors suggest that antiscarring agents are not necessary routinely, and mention the side effects noted using subconjunctival 5-fluorouracil, particularly the corneal complications. ${ }^{11}$ Single intraoperative applications of 5-fluorouracil, $\beta$ irradiation, or mitomycin $c$ are much more convenient in this patient group and are associated with virtually no corneal toxicity. Unfortunately, mitomycin $\mathrm{c}$ at current clinical doses has a marked cytotoxic effect on fibroblasts. ${ }^{12}$ This is associated with side effects such as flat anterior chambers, hypotony, choroidal effusions, and endophthalmitis in patients with congenital glaucoma, and is probably not justified in primary trabeculectomy. ${ }^{13}$ Gentler agents such as a single intraoperative application of 5 -fluorouracil ${ }^{14}{ }^{15}$ or $750 \mathrm{cGy}$ of $\beta$ irrradiation ${ }^{7}$ result in lower average pressures without hypotony and may increase the long term success rate of trabeculectomy without any obvious increase in side effects such as cystic avascular blebs, hypotony, or endophthalmitis. The use of one of these weaker agents should be considered, particularly in patients with risk factors for failure such as a corneal diameter $>14 \mathrm{~mm} \mathrm{Hg}$.

Goniotomy and trabeculotomy have traditionally been regarded as the procedures of choice for the infantile glaucomas, particularly primary congenital glaucoma, because of high reported success rates. Goniotomy has the advantage of preserving the conjunctiva for future use, but does require a clear cornea and may have to be repeated more than once. ${ }^{16}$ However, the cornea can be cleared in more than $90 \%$ of patients with primary congenital glaucoma following epithelial removal. ${ }^{16}$ Q-switched neodymium-YAG laser goniotomy, although initially promising ${ }^{17}$ has been disappointing in the long term. Trabeculotomy has the advantage of being possible in the few eyes in which visualisation is not possible, but has the disadvantage of damaging the conjunctiva, although it can be 
performed inferotemporally to minimise the effect on the superior conjunctiva. In addition to these two procedures, it has recently been suggested that combined trabeculectomy/trabeculotomy is superior to trabeculectomy, trabeculotomy, or goniotomy with a 2 year success rate of $93.5 \% .^{18} \mathrm{~A}$ disadvantage of the combined procedure is the fact that the sclerostomy has to be placed more posteriorly than with trabeculectomy alone, predisposing to iris and ciliary body incarceration.

Inevitably, the high success rates with any of these procedures, as in the current report by Fulcher et al, come from centres or individuals with experience and expertise with the infantile glaucomas and surgical procedures in these eyes. Of 335 eyes of 210 patients with primary congenital glaucoma treated with initial goniotomy at Moorfields Eye Hospital and followed, in some cases, for up to 30 years, $93 \%$ of eyes were still controlled at 5 years, ${ }^{16}$ the time period of the current study. Similar figures have been obtained by other specialist centres for both goniotomy and trabeculotomy and this is well summarised by Deluise and Anderson. ${ }^{19}$ However, when goniotomy, trabeculotomy, and trabeculectomy were performed on Palestinian Arab children by general ophthalmologists, Elder found a success rate at 5 years of approximately $20 \%, 35 \%$, and $55 \%$ respectively. ${ }^{6}$ By way of contrast, at a specialist centre in the Middle East, trabeculotomy had a success rate of $67 \%$ versus $54 \%$ for trabeculectomy, but with a follow up of approximately only 1 year. Significant complications such as vitreous loss and endophthalmitis occurred only in the trabeculectomy group. ${ }^{20}$ Unfortunately, because of the relative rarity of this group of conditions, none of the comparative studies of treatment techniques in congenital glaucoma have been prospective controlled studies.

So what is the best primary surgical treatment for the infantile glaucomas, particularly primary congenital glaucoma? The main message from the current paper and the literature is that these rare patients do best at centres that have appropriate experience and expertise. Performed at their best, all the techniques available have advantages and disadvantages and have potentially excellent success rates if carried out correctly. However, if referral to such centres is impossible, as may be the case in some areas of the world, then trabeculectomy (possibly coupled with a gentler antiscarring agent such as a single intraoperative application of 5 -fluorouracil or $\beta$ irradiation $)^{21}$ is probably the most appropriate primary surgical treatment for use by ophthalmologists who are not experienced in goniotomy or trabeculotomy.

PENG T KHAW

Glaucoma Unit and Department of Pathology,

Moorfields Eye Hospital and Institute of Ophthalmology,

London

1 Jaafar MS. Care of the infantile glaucoma patient. In: Reinecke RD, ed. Ophthalmology annual. New York: Raven Press, 1988:15-37.

2 Gilbert CE. Causes of blindness and severe visual impairment in children in Chile. Devel Med Child Neurol 1994;36:326-33.

3 Thylefors B, Negrel A. The global impact of glaucoma. Bull World Health Organ 1994;72:323-6.

4 Beauchamp GR, Parks MM. Filtering surgery in children: barriers to success. Ophthalmology 1979;86:170-80.

5 Hauviller V. Gonioscopic findings in trabeculectomies in young children. $\mathcal{F}$ Pediatr Ophthalmol Strabismus 1989;26:133-5.

6 Elder MJ. Congenital glaucoma in the West Bank and Gaza strip. $\mathrm{Br} f \mathrm{Oph}$ thalmol 1993;77:413-6.

7 Miller MH, Rice NS. Trabeculectomy combined with beta irradiation for congenital glaucoma. Brf Ophthalmol 1991;75:584-90.

8 The Fluorouracil Filtering Surgery Study Group. Fluorouracil filtering surThe Fluorouracil Filtering Surgery Study Group. Fluorouracil filtering

gery study one-year follow-up. Am f Ophthalmol 1989;108:625-35.
Shaffer RN. Prognosis in primary infantile glaucoma (trabeculodysgenesis) In: Krieglstein G, Leydhecker W, eds. Glaucoma update II. Berlin: SpringerVerlag, 1983:185-8.

10 Burke JP, Bowell R. Primary trabeculectomy in congenital glaucoma. $\mathrm{Br} f$ Ophthalmol 1989;73:186-90.

11 Knapp A, Heuer DK, Stern GA, Driebe WT. Serious corneal complications of glaucoma filtering surgery with postoperative 5-fluorouracil. $\mathrm{Am} \mathrm{f} \mathrm{Oph-}$ thalmol 1987;103:183-7.

12 Khaw PT, Sherwood MB, MacKay SLD, Rossi MJ, Schultz GS. Five-minute treatments with fluorouracil, floxuridine, and mitomycin have long-term effects on human Tenon's capsule fibroblasts. Arch Ophthalmol long-term effects

13 Susann R Jr, Oltragge EW, Carani JCE, Nicolela MT. Mitomycin as adjunct chemotherapy with trabeculectomy in congenital and developmental glaucomas. F Glaucoma 1995;4:151-7.

14 Lanigan LP, Stuermer J, Baez KA, Hitchings RA, Khaw PT. Single intraoperative applications of 5-fluorouracil during filtration surgery: early results. Br f Ophthalmol 1994;78:33-7.

15 Feldman RM, Dietze PJ, Gross RL, Oram O. Intraoperative 5-fluorouracil administration in trabeculectomy. F Glaucoma 1994;3:302-7.

16 Russell-Eggitt IM, Rice NS, Jay B, Wyse RK. Relapse following goniotomy for congenital glaucoma due to trabecular dysgenesis. Eye 1992;6:197-200.

17 Senft SH, Tomey KF, Traverso CE. Neodymium-YAG laser goniotomy vs surgical goniotomy. A preliminary study in paired eyes. Arch Ophthalmo 1989;107:1773-6.

18 Elder MJ. Combined trabeculotomy-trabeculectomy compared with primary trabeculectomy for congenital glaucoma. Br f Ophthalmol 1994;78: mary trab

19 DeLuise VP, Anderson DR. Primary infantile glaucoma (congenital glaucoma). Surv Ophthalmol 1983;28:1-19.

20 Debnath SC, Teichmann KD, Salamah K. Trabeculectomy versus trabeculotomy in congenital glaucoma. Br F Ophthalmol 1989;73:608-11.

21 Khaw PT, Rice NSC, Baez KA. The congenital glaucomas. In: El Sayyad F, Spaeth GL, Shield MB, Hitchings RA, eds. The refractory glaucomas. Tokyo: Igaku-Shoin Medical Publishers Inc, 1995:1-21.

\section{The challenge of HIV/AIDS related eye disease}

As the predominant disease of the late 20th century, AIDS has thrived on great social change and globalisation of the world's economies and cultures. For most public health authorities, particularly in developing countries, the fact that the human immunodeficiency virus (HIV) affects the eye is simply a curiosity. As yet, little interest in HIV/AIDS has been expressed by the international eye care nongovernmental organisations; perhaps this should change.

There is a large body of literature now which describes the ocular manifestations of HIV/AIDS in developed countries and tremendous strides have been made in our understanding of cytomegalovirus (CMV) retinitis. Many ophthalmologists are unaware that the pattern of ocular morbidity associated with HIV/AIDS in developed countries is not representative of the epidemiology of the disease in developing countries. Investigations such as that carried out in Uganda and Malawi by Waddell and colleagues and reported in this issue of the BFO (p 503) are an important contribution to our understanding of the ocular manifestations of HIV/AIDS in Africa. This report and others from east Africa and South America make it clear that the epidemiology of the ocular manifestations of HIV/AIDS is not well understood. There have been no reports from west Africa, where HIV-2 infection predominates. There is a real paucity of information from Asia where, by the year 2000 , it is estimated that there will be 1.3 million HIV infections per year, over $60 \%$ of the world's total.

As reports by Kestelyn et $a l^{1}$ and Lewallen et $a l^{2}$ have demonstrated, CMV retinitis is relatively rare in Africa; this is probably due to the fact that mortality often occurs early in the course of HIV infection, before clinical AIDS develops. ${ }^{3}$ In developed countries, however, life expectancy after HIV seroconversion has increased to around 12 years; new classes of prophylactic drugs are delaying the onset of AIDS defining illnesses (although CMV retinitis is not one 